\title{
Vitamin D and Diagnosis of COPD in a Working Population
}

Koichi Nishimura1*, Miyoko Ogasawara ${ }^{2}$, Mariko Makita², Kazuhito Nakayasu ${ }^{3}$, Yoshinori Hasegawa ${ }^{4}$ and Satoshi Mitsuma²

${ }^{1}$ Department of Pulmonary Medicine, National Center for Geriatrics and Gerontology, Obu, Japan

${ }^{2}$ Niigata Association of Occupational Health Incorporated, Niigata, Japan

${ }^{3}$ Data Research Section, Kondo P.P. Inc., Osaka, Japan

${ }^{4}$ Department of Medicine, Division of Respiratory Medicine, Nagoya University Graduate School of Medicine, Nagoya, Japan

\begin{abstract}
Background: Some epidemiologic studies have proven the possible association between the serum level of 25 -hydroxy vitamin $\mathrm{D}[25(\mathrm{OH}) \mathrm{D}]$ and the forced expiratory volume in 1 second $\left(\mathrm{FEV}_{1}\right)$ or chronic obstructive pulmonary disease (COPD).
\end{abstract}

Purpose: To investigate whether serum concentrations of $25(\mathrm{OH}) \mathrm{D}$ play a role in the diagnosis of COPD in a working population.

Patients and methods: A total of 299 industrial workers aged $\geq 40$ years performed spirometry and had their serum level of $25(\mathrm{OH}) \mathrm{D}$ measured.

Results: The prevalence of COPD defined by the fixed ratio was $14.1 \%$. Mean $25(\mathrm{OH}) \mathrm{D}$ levels did not differ significantly between subjects with COPD and those without COPD as defined by the fixed ratio $(24.6 \mathrm{ng} / \mathrm{mL} \pm 6.7 \mathrm{ng} /$ $\mathrm{mL}$ in subjects with COPD vs. $24.0 \mathrm{ng} / \mathrm{mL} \pm 5.9 \mathrm{ng} / \mathrm{mL}$ in subjects without COPD; not significantly different). According to an Endocrine Society Clinical Practice Guideline released in the US in 2011, vitamin D insufficiency, defined as $25(\mathrm{OH}) \mathrm{D}$ levels of $<30 \mathrm{ng} / \mathrm{mL}$, was present in $252(84.2 \%)$ out of the 299 participants, and vitamin D deficiency, defined as $25(\mathrm{OH}) \mathrm{D}$ levels of $<20 \mathrm{ng} / \mathrm{mL}$, was found in $80(26.8 \%)$ subjects. Forced expiratory volume in 1 second $\left(\mathrm{FEV}_{1}\right)$, forced vital capacity (FVC), FEV, /FVC and the prevalence of subjects with COPD were not significantly different among the three groups with different $25(\mathrm{OH}) \mathrm{D}$ levels ( $\geqq 30 \mathrm{ng} / \mathrm{mL}, \geqq 20$ and $<30 \mathrm{ng} / \mathrm{mL}$ and $<20 \mathrm{ng} / \mathrm{mL}$ ). Statistically significant correlations were not found between any measurements obtained from spirometry, including FEV $\mathrm{FEV}_{1} /$ FVC, and 25(OH)D levels.

Conclusion: Although vitamin $D$ insufficiency and deficiency were frequently observed in the present study, the serum 25(OH)D concentration was not different between COPD and non-COPD subjects in a working population. The association between 25(OH)D levels and COPD did not meet a level of statistical significance in the present study conducted in a working population.

Keywords: Chronic obstructive pulmonary disease (COPD); Forced expiratory volume in 1 second $\left(\mathrm{FEV}_{1}\right)$; Airflow limitation; Lower limit of normal (LLN); 25-hydroxy vitamin D [25(OH)D]

\section{Introduction}

It has been emphasized that spirometry is essential in making a diagnosis of chronic obstructive pulmonary disease (COPD) since COPD is defined by airflow limitation measured using spirometry [1]. However, COPD remains under-diagnosed, with the diagnosis being commonly missed or delayed until the disease is advanced. Since COPD screening by spirometry may be a little expensive, the concept of case-identification or case-finding to pre-select candidates for spirometry has been proposed $[2,3]$ and the possibility of identifying people at high risk for COPD has been studied. So far, two presumptive methods have been reported for target case identification to reduce the burden of COPD. One method uses a portable device called a handheld spirometer instead of a conventional spirometer [4], and the other is a screening method using specific questionnaires [2,5]. Researchers have also been investigating the discriminative properties of various biomarkers; however, there is still no known biomarker useful for diagnosing or screening COPD.

Although vitamin $\mathrm{D}$ is not a biomarker, there have been some studies to determine whether vitamin D plays a role in some respiratory diseases. An association between vitamin D deficiency and decreased pulmonary functions as well as airflow limitation in asthma patients has been suggested [6]. There have been some reports of the possible association of acute exacerbation of COPD with vitamin D deficiency although there have also been other reports that no association exists [7,8]. Martineau et al. [9] reported that vitamin $\mathrm{D}_{3}$ supplementation protected against moderate or severe exacerbation in subjects with COPD with low 25-hydroxyvitamin D [25(OH)D] level. The discussion is still continuing.

The relation between stable COPD and vitamin D level has also been investigated. Researchers at the Third National Health and Nutrition Survey (NHANES III) have found strong positive relations between serum $25(\mathrm{OH}) \mathrm{D}$ and both forced expiratory volume in 1 second $\left(\mathrm{FEV}_{1}\right)$ and forced vital capacity $(\mathrm{FVC})$ in the general population [10]. Janssens et al. [11] demonstrated that vitamin D deficiency, as assessed by $25(\mathrm{OH}) \mathrm{D}$ levels in serum, is common in patients with COPD and correlates with the severity of the disease as measured by FEV $_{1}$. However, in the Hertfordshire Cohort Study, serum 25(OH)D concentrations were not related to $\mathrm{FEV}$, but were positively associated with COPD [12]. The Evaluation of COPD Longitudinally to Identify Predictive Surrogate Endpoints (ECLIPSE) study also demonstrated a relationship between vitamin D status and emphysema, and confirms associations between vitamin D status and $\mathrm{FEV}_{1}[13]$. Therefore, some

*Corresponding author: Koichi Nishimura, Department of Pulmonary Medicine, National Center for Geriatrics and Gerontology, 7-430, Morioka-cho, Morioka, Obu, Aichi, Japan, Tel: +81-562-46-2311; Fax: +81-562-44-8518; E-mail: koichi-nishimura@nifty.com

Received June 07, 2016; Accepted July 12, 2016; Published July 15, 2016

Citation: Nishimura K, Ogasawara M, Makita M, Nakayasu K, Hasegawa Y, et al (2016) Vitamin D and Diagnosis of COPD in a Working Population. J Pulm Respir Med 6: 359. doi:10.4172/2161-105X.1000359

Copyright: (c) 2016 Nishimura K, et al. This is an open-access article distributed under the terms of the Creative Commons Attribution License, which permits unrestricted use, distribution, and reproduction in any medium, provided the original author and source are credited. 
epidemiologic studies have proven the possible association between serum levels of 25(OH)D and $\mathrm{FEV}_{1}$ [14] and it has been reported that vitamin $\mathrm{D}$ deficiency is frequently found in subjects with COPD.

We hypothesized that serum concentration of $25(\mathrm{OH}) \mathrm{D}$ may play a role in the diagnosis of COPD. Industrial workers aged $\geq 40$ years performed spirometry and completed measurements of the serum level of $25(\mathrm{OH}) \mathrm{D}$. The authors investigated the relationship between vitamin $\mathrm{D}$ and airflow limitation in the participants.

\section{Material and Methods}

\section{Subjects}

The study was conducted between October and November 2013 at the Niigata Association of Occupational Health Incorporated, Niigata, Japan. The study subjects were participants undergoing comprehensive health examination in Japan over forty years old at this Association. They were mostly company employees with the financial support of companies, came from various workplaces or from many firms and had heterogeneous background. All had comprehensive health screening, including conventional spirometry, as well as a chest radiographs. The serum $25(\mathrm{OH}) \mathrm{D}$ level was measured in all the participants. The exclusion criteria for this analysis included:

1) abnormal findings for the pulmonary parenchyma or chest wall revealed on chest radiographs;

2) thoracotomy received in the past;

3) any admission to a hospital during the preceding three months (except hospitalization for routine tests);

4) any physician-diagnosed pulmonary disease including lung cancer, pulmonary tuberculosis, bronchiectasis and nontuberculosis mycobacteriosis;

5) a history of cancer or malignant disorders; and

6) unstable complications of cardiovascular, neuromuscular, renal, endocrinological, haematological, gastrointestinal, or hepatic co-morbidities. Written informed consent was obtained from all participants. The present study was approved by the ethics committee of the Niigata Association of Occupational Health Incorporated. In this study, COPD was spirometrically defined as airflow limitation with a $\mathrm{FEV}_{1} / \mathrm{FVC}$ less than a fixed ratio, 0.7, or the lower limit of normal (LLN) without bronchodilator administration.

\section{Methods}

All eligible subjects finished the following examinations on the same day. The serum $25(\mathrm{OH}) \mathrm{D}$ level was measured by use of competitive protein binding assay in all the participants. Spirometry was performed with the use of nose clips in the sitting position with an SP-370 ${ }^{\mathrm{TM}}$ Spirometer (Fukuda Denshi Co., Ltd., Tokyo, Japan).
All measurements were performed by a laboratory technician (MO) in accordance with guidelines published by the American Thoracic Society and the European Respiratory Society [15]. The spirometric $\mathrm{FVC}$ and $\mathrm{FEV}_{1}$ values were the largest $\mathrm{FVC}$ and largest $\mathrm{FEV}_{1}$ selected from data obtained from at least three acceptable forced expiratory curves, even if these values were not obtained from the same curve [16]. The predicted values for pulmonary function were calculated based on the proposal from the Japanese Respiratory Society [17]. The LLN for the Japanese population was calculated using the method described by Osaka et al. [18]. The participants also answered additional questions to investigate their smoking status and history. Information about their radiographic findings was obtained from annual health examinations.

All results are expressed as means \pm SD. A p value of less than 0.05 was considered to be statistically significant. All statistical analysis was performed using IBM SPSS Statistics 21.0 (International Business Machines Corp, Armonk, New York, USA).

\section{Results}

A total of 301 subjects participated at the beginning of the present study. However, two subjects were excluded from the data analysis because of uncertainty in their smoking history. Therefore, a total of 299 consecutive subjects ( 283 males) were analyzed. The average age of the subjects was 53.5 years. The mean $\mathrm{FEV}_{1} / \mathrm{FVC}$ ratio was $77.2 \%$, ranging from $40.2 \%$ to $94.4 \%$. Their demographic details are shown in Table 1.

Using the fixed ratio of the $\mathrm{FEV}_{1} / \mathrm{FVC}<0.7,42$ subjects were diagnosed with COPD, which included 42 out of the 283 males (14.8\%) and 0 out of the 16 females (0\%). Using the classification of severity of airflow limitation in COPD of the Global Initiative for Chronic Obstructive Lung Disease (GOLD) criteria, 26 were in GOLD 1, 15 in GOLD 2 and 1 in GOLD 3. Using the lower limit of normal (LLN) definition, 16 subjects had COPD, which included 15 males $(5.3 \%)$ and 1 female (6.3\%), but 283 were not considered to have COPD. The overall prevalence of COPD was $14.0 \%$, as defined by the fixed ratio, and $5.4 \%$ as defined by the LLN.

The mean 25(OH)D level of all 299 participants was $24.1 \mathrm{ng} /$ $\mathrm{mL}$. The serum level of $25(\mathrm{OH}) \mathrm{D}$ was $24.6 \mathrm{ng} / \mathrm{mL} \pm 6.7 \mathrm{ng} / \mathrm{mL}$ in 42 subjects with COPD defined by the fixed ratio and $24.0 \mathrm{ng} / \mathrm{mL} \pm$ $5.9 \mathrm{ng} / \mathrm{mL}$ in 257 subjects without COPD defined by the fixed ratio. There was no statistically significantly difference between the two spirometrically divided groups $(\mathrm{p}=0.543$, Student $\mathrm{t}$-test). The serum $25(\mathrm{OH}) \mathrm{D}$ concentration was $24.0 \mathrm{ng} / \mathrm{mL} \pm 5.7 \mathrm{ng} / \mathrm{mL}$ in 16 subjects with COPD defined by the LLN and $24.1 \mathrm{ng} / \mathrm{mL} \pm 6.0 \mathrm{ng} / \mathrm{mL}$ in 283 subjects without COPD defined by the LLN. These results were not statistically significantly different $(\mathrm{p}=0.916)$.

According to an Endocrine Society Clinical Practice Guideline released in the US in 2011 [19], vitamin D insufficiency, defined as $25(\mathrm{OH}) \mathrm{D}$ levels of $<30 \mathrm{ng} / \mathrm{mL}$, was present in $252(84.2 \%)$ out of 299

\begin{tabular}{|c|c|c|c|c|c|c|c|}
\hline & Total Subjects & Age & Male & $\begin{array}{l}\text { Cumulative } \\
\text { Smoking }\end{array}$ & $\begin{array}{l}\text { Prior Diagnosis } \\
\text { of COPD }\end{array}$ & FEV $_{1}$ & $\mathrm{FEV}_{1} / \mathrm{FVC}$ \\
\hline & number & years & Number (\%) & pack-years & Number (\%) & \%pred & $\%$ \\
\hline All subjects & 299 & $53.5 \pm 8.2$ & $283(94.6 \%)$ & $27.2 \pm 16.8$ & $3(1 \%)$ & $91.2 \pm 12.0$ & $77.2 \pm 6.4$ \\
\hline non-COPD defined by fixed ratio & 257 & $53.0 \pm 8.1$ & $241(93.8 \%)$ & $25.6 \pm 15.9$ & $2(0.8 \%)$ & $92.8 \pm 11.1$ & $79.0 \pm 4.6$ \\
\hline COPD defined by fixed ratio & 42 & $56.5 \pm 8.2$ & $42(100 \%)$ & $37.4 \pm 18.8$ & $1(2.4 \%)$ & $81.0 \pm 12.3$ & $66.0 \pm 4.0$ \\
\hline non-COPD defined by LLN & 283 & $53.3 \pm 8.1$ & $268(94.7 \%)$ & $26.7 \pm 16.6$ & $3(1.1 \%)$ & $92.1 \pm 11.1$ & $78.0 \pm 5.4$ \\
\hline COPD defined by LLN & 16 & $55.6 \pm 9.6$ & $15(93.8 \%)$ & $37.2 \pm 18.4$ & $0(0 \%)$ & $73.7 \pm 14.8$ & $62.8 \pm 5.0$ \\
\hline
\end{tabular}

$\mathrm{FEV}_{1}$ : Forced expiratory volume in 1 second; FVC: Forced vital capacity; COPD: Chronic obstructive pulmonary disease; LLN: Lower limit of normal.

Table 1: Demographic details and spirometric results for all 299 subjects. 
participants, and vitamin D deficiency, defined as $25(\mathrm{OH}) \mathrm{D}$ levels of $<20 \mathrm{ng} / \mathrm{mL}$, was found in $80(26.8 \%)$ subjects. There was none with severe deficiency $(<10 \mathrm{ng} / \mathrm{ml})$ in the present study. $\mathrm{FEV}_{1}$ was $3.13 \mathrm{~L} \pm$ $0.65 \mathrm{~L}(93.4 \% \pm 12.6 \%$ predicted $)$ in 47 subjects with $25(\mathrm{OH}) \mathrm{D}$ levels of $\geq 30 \mathrm{ng} / \mathrm{mL}, 3.08 \mathrm{~L} \pm 0.58 \mathrm{~L}(90.7 \% \pm 12.1 \%$ predicted $)$ in 172 subjects with $25(\mathrm{OH}) \mathrm{D}$ levels of $\geq 20$ and $<30 \mathrm{ng} / \mathrm{mL}$ and $3.21 \mathrm{~L} \pm 0.52 \mathrm{~L}$ $(90.8 \% \pm 11.4 \%$ predicted $)$ in 80 subjects with $25(\mathrm{OH}) \mathrm{D}$ levels of $<20$ $\mathrm{ng} / \mathrm{mL}(\mathrm{p}=0.245$ and 0.392 , ANOVA). FVC and FEV $/$ FVC were not significantly different among the three groups with different $25(\mathrm{OH})$ $\mathrm{D}$ levels. The number of subjects diagnosed with COPD as defined by the fixed ratio or by the LLN was 6 and 3 out of 47 subjects $(12.8 \%$ and $6.4 \%$ ) with $25(\mathrm{OH}) \mathrm{D}$ levels of $\geq 30 \mathrm{ng} / \mathrm{mL}, 27$ and 9 out of 172 subjects $(15.7 \%$ and $5.2 \%)$ with $25(\mathrm{OH}) \mathrm{D}$ levels of $\geq 20$ and $<30 \mathrm{ng} / \mathrm{mL}$ and 9 and 4 out of 80 subjects ( $11.3 \%$ and $5.0 \%$ ) with $25(\mathrm{OH}) \mathrm{D}$ levels of $<20$ $\mathrm{ng} / \mathrm{mL}$, respectively. The prevalence of subjects with COPD was not significantly different among the three groups with different $25(\mathrm{OH})$ D levels (Table 2).

Table 3 shows serum 25(OH)D concentrations across quintiles and lung function parameters and the prevalence of COPD by quintiles. The associations of level of 25(OH)D with $\mathrm{FEV}_{1}, \mathrm{FVC}$ and $\mathrm{FEV}_{1} / \mathrm{FVC}$ as well as the prevalence of COPD did not show a statistically significant difference among the 25-hydroxyl vitamin D quintiles.

Simple correlations between pulmonary function test parameters and serum 25(OH)D concentrations were analyzed. Pearson's correlation coefficients between the serum 25(OH)D concentration and $\mathrm{FEV}_{1}(\mathrm{~L}), \mathrm{FEV}_{1}$ (\% predicted) and $\mathrm{FEV}_{1} / \mathrm{FVC}$ were $-0.073,0.025$ and -0.065 , respectively. Contrary to our expectations, none of the relationships was significant (all, $\mathrm{p}<0.01$ ). Using the fixed ratio by spirometry as the definition of airflow limitation, a receiver operating characteristic (ROC) curve was analyzed to set a cut-off point for the serum $25(\mathrm{OH}) \mathrm{D}$ concentration. The best $25(\mathrm{OH}) \mathrm{D}$ concentration for the largest sum of sensitivity and specificity was $24.8 \mathrm{ng} / \mathrm{mL}$. The area under the ROC curve was 0.519 (95\% CI: $0.426-0.613$ ). Therefore, the level of agreement in the definition of airflow limitation using a cut off value of 24.8 for $25(\mathrm{OH}) \mathrm{D}$ concentration was poor with sensitivity of $54.2 \%$, specificity of $58.8 \%$ and diagnostic accuracy of $57.9 \%$.

\section{Discussion}

This study showed that serum concentrations of 25-hydroxy vitamin $\mathrm{D}$ cannot be used in the diagnosis of COPD, and that measurements of serum $25(\mathrm{OH}) \mathrm{D}$ concentrations prior to spirometry will not play a role in case determination or in screening high-risk subjects with possible COPD. Since COPD is defined by airflow limitation measured using spirometry, two presumptive methods have been reported for targeted case identification to reduce the burden of COPD. One method uses a portable device called a hand-held spirometer instead of a conventional spirometer, and the other is a screening method using specific questionnaires. The results of the present study proved that the discriminative property of $25(\mathrm{OH}) \mathrm{D}$ is far less effective than the handheld spirometer, specific questionnaires, or a combination of both.

Although previous studies have reported a statistically significant association between vitamin $\mathrm{D}$ deficiency and airflow limitation indices as well as with COPD prevalence, we found no statistically significant relationship in either case. One possible reason for our negative results is the study design as we had a relatively low number of participants. The study that reported a positive association between vitamin D deficiency and airflow limitation had more participants. Our study was also conducted on a working population; therefore, participants were healthier and more homogenous compared to those in past studies. There were some participants with airflow limitation, but none of them had severe COPD. Our results were probably not statistically significant because there was no one with more severe COPD among our participants.

The participants in this study were industrial workers over 40 years old in Japan. The prevalence of COPD defined by the fixed ratio was $14.0 \%$, whereas that defined by the LLN was $5.4 \%$. Although there have been only a few population-based surveys regarding the prevalence of COPD in Japan, these figures are a little higher than those reported in the Nippon COPD Epidemiology (NICE) study, in which the prevalence defined by the fixed ratio was $10.9 \%$ [20]. Similarly, in a community-based annual health check, Osaka et al. [18] also reported that $10.6 \%$ had COPD as defined by the fixed ratio and $6.4 \%$ had COPD

\begin{tabular}{|c|c|c|c|c|c|}
\hline & \multicolumn{5}{|c|}{ 25-hydroxyl vitamin $D(\mathrm{ng} / \mathrm{mL})$} \\
\hline & mean & median & SD & $\max$. & $\min$. \\
\hline All subjects & 24.1 & 23.4 & 6.0 & 56.0 & 10.2 \\
\hline non-COPD defined by fixed ratio & 24.0 & 23.4 & 5.9 & 56.0 & 10.2 \\
\hline COPD defined by fixed ratio & 24.6 & 24.9 & 6.7 & 51.5 & 14.0 \\
\hline non-COPD defined by LLN & 24.1 & 23.4 & 6.0 & 56.0 & 10.2 \\
\hline COPD defined by LLN & 24.0 & 23.7 & 5.7 & 33.7 & 15.3 \\
\hline
\end{tabular}

The serum 25-hydroxyl vitamin D concentration was not different between COPD and non-COPD subjects; COPD: Chronic obstructive pulmonary disease; LLN: Lower limit of normal.

Table 2: Comparison of the serum levels of 25-hydroxyl vitamin D.

\begin{tabular}{|c|c|c|c|c|c|c|c|c|}
\hline \multirow{3}{*}{$\begin{array}{c}\text { 25(OH)D quintile } \\
\text { (ng/mL) }\end{array}$} & \multirow{3}{*}{$\begin{array}{c}\text { Total Subjects } \\
\text { number }\end{array}$} & \multirow{2}{*}{ FEV $_{1}$} & \multirow{2}{*}{$\mathrm{FEV}_{1}$} & \multirow{2}{*}{ FEV1/FVC } & \multirow{2}{*}{ FVC } & \multirow{2}{*}{ FVC } & \multicolumn{2}{|c|}{ COPD defined by } \\
\hline & & & & & & & fixed ratio & LLN \\
\hline & & liters & $\%$ pred & $\%$ & liters & $\%$ pred & \multicolumn{2}{|c|}{ Number (\%) } \\
\hline$<19.0$ & 59 & $3.26 \pm 0.47$ & $91.6 \pm 9.9$ & $78.3 \pm 6.7$ & $4.18 \pm 0.58$ & $99.8 \pm 9.6$ & $6(10 \%)$ & $3(5 \%)$ \\
\hline $19.0-22.0$ & 55 & $3.01 \pm 0.63$ & $88.7 \pm 13.3$ & $76.7 \pm 5.9$ & $3.92 \pm 0.72$ & $97.8 \pm 13.0$ & $10(18 \%)$ & $2(4 \%)$ \\
\hline $22.1-25.3$ & 63 & $3.18 \pm 0.59$ & $92.8 \pm 13.9$ & $77.9 \pm 6.7$ & $4.07 \pm 0.62$ & $100.7 \pm 12.4$ & $6(10 \%)$ & $5(8 \%)$ \\
\hline $25.4-29.0$ & 62 & $3.05 \pm 0.54$ & $89.6 \pm 10.8$ & $75.6 \pm 6.7$ & $4.03 \pm 0.66$ & $99.9 \pm 11.7$ & $14(23 \%)$ & $3(5 \%)$ \\
\hline$\geq 29.1$ & 60 & $3.08 \pm 0.63$ & $92.8 \pm 11.5$ & $77.3 \pm 5.6$ & $4.00 \pm 0.80$ & $100.7 \pm 12.1$ & $6(10 \%)$ & $3(5 \%)$ \\
\hline Total & 299 & $3.12 \pm 0.58$ & $91.2 \pm 12.0$ & $77.2 \pm 6.4$ & $4.04 \pm 0.68$ & $99.8 \pm 11.8$ & 42 & 16 \\
\hline
\end{tabular}

$\mathrm{FEV}_{1}, \mathrm{FVC}, \mathrm{FEV}_{1} / \mathrm{FVC}$ and the prevalence of COPD were not statistically significantly different among the 25-hydroxyl vitamin D quintiles; 25(OH)D: 25-hydroxyl vitamin D; $\mathrm{FEV}_{1}$ : Forced expiratory volume in 1 second; FVC: Forced vital capacity; COPD: Chronic obstructive pulmonary disease; LLN: Lower limit of normal. 
as defined by the LLN. Thus, the prevalence of COPD reported in this study may be a little higher or similar to previous studies in Japan.

Although it has been reported that vitamin D insufficiency and deficiency are common in smokers with COPD, vitamin D insufficiency was present in $84 \%$ of our study participants and vitamin $\mathrm{D}$ deficiency in $25 \%$ of our study participants, showing that many participants had a very low level of vitamin $\mathrm{D}$ even though they did not have COPD. Since vitamin D is supplied by food or sunlight exposure, vitamin D concentrations are largely influenced by the duration of sunshine, obesity, and calcium intake. Therefore, 25(OH)D concentration probably varies by region. The definitions of vitamin $\mathrm{D}$ insufficiency as $25(\mathrm{OH}) \mathrm{D}$ levels of $<30 \mathrm{ng} / \mathrm{mL}$ and vitamin D deficiency as $25(\mathrm{OH})$ D levels of $<20 \mathrm{ng} / \mathrm{mL}$ were presented as Clinical Practice Guidelines by the Endocrine Society in the USA, and it is unclear whether these standards are valid in Japan. As far as we know, there are no reports on the normal level of 25(OH)D in Japan.

It is known that vitamin D plays an important role in bone diseases such as rickets and osteomalacia. There are also some reports that suggested associations with neurological disorders such as diabetes, multiple sclerosis as well as myocardial infarction and hypertension. Although some have reported the blood 25(OH)D levels necessary to prevent premature death, falls, cancer, and respiratory tract infections, COPD was not discussed in the preventive role of vitamin D. Since our study did not find an association between blood 25(OH)D levels and the COPD diagnosis, we did not find evidence to support the hypothesis that the vitamin D level is related to the onset of COPD. If there is any relationship between the vitamin D level and COPD, the interactions may be more subtle. The mechanisms of COPD onset remain largely unknown, and should be studied more in the future.

\section{Conclusion}

Although vitamin D insufficiency and deficiency were frequently observed in the present study, the serum $25(\mathrm{OH}) \mathrm{D}$ concentrations were not different between COPD and non-COPD subjects in a working population. The association between $25(\mathrm{OH}) \mathrm{D}$ levels and COPD did not meet the level of statistical significance in the present study conducted in a working population.

\section{Acknowledgments}

This study was partly supported by the Research Funding for Longevity Sciences (27-10) from the National Center for Geriatrics and Gerontology (NCGG), Japan. This study was conducted at the Niigata Association of Occupational Health Incorporated, Niigata, Japan.

\section{Author Contributions}

$\mathrm{KN}$ planned the study design, and was a major contributor in writing the manuscript. MO and MM participated in the data collection and the care of the participants. KN performed the statistical analysis. $\mathrm{YH}$ contributed to the data analysis and interpretation and editing of the manuscript. SM was the physician responsible for all participants. All authors read and approved the final manuscript.

\section{References}

1. Global Initiative for Chronic Obstructive Lung Disease (GOLD) (2011) The global strategy for the diagnosis, management and prevention of COPD.
2. Price DB, Tinkelman DG, Nordyke RJ, Isonaka S, Halbert RJ, et al. (2006) Scoring system and clinical application of copd diagnostic questionnaires. Chest 129: 1531-1539.

3. Soriano JB, Zielinski J, Price D (2009) Screening for and early detection of chronic obstructive pulmonary disease. Lancet 374: 721-732.

4. Nishimura K, Nakayasu K, Kobayashi A, Mitsuma S (2011) Case identification of subjects with airflow limitations using the handheld spirometer "Hi-Checker ${ }^{\mathrm{TM}}$ " : comparison against an electronic desktop spirometer. COPD 8: 450-455.

5. Hanania NA, Mannino DM, Yawn BP, Mapel DW, Martinez FJ, et al. (2010) Predicting risk of airflow obstruction in primary care: Validation of the lung function questionnaire (Ifq). Respir Med 104: 1160-1170.

6. Li F, Peng M, Jiang L, Sun Q, Zhang K, et al. (2011) Vitamin d deficiency is associated with decreased lung function in chinese adults with asthma. Respiration 81: 469-475.

7. Kunisaki KM, Niewoehner DE, Connett JE (2012) Vitamin d levels and risk of acute exacerbations of chronic obstructive pulmonary disease: A prospective cohort study. Am J Respir Crit Care Med 185: 286-290.

8. Malinovschi A, Masoero M, Bellocchia M, Ciuffreda A, Solidoro P, et al. (2014) Severe vitamin $D$ deficiency is associated with frequent exacerbations and hospitalization in copd patients. Respir Res 15: 131.

9. Martineau AR, James WY, Hooper RL, Barnes NC, Jolliffe DA, et al. (2015) Vitamin d3 supplementation in patients with chronic obstructive pulmonary disease (vidico): A multicentre, double-blind, randomised controlled trial. Lancet Respir Med 3: 120-130.

10. Black PN, Scragg R (2005) Relationship between serum 25-hydroxyvitamin d and pulmonary function in the third national health and nutrition examination survey. Chest 128: 3792-3798.

11. Janssens W, Bouillon R, Claes B, Carremans C, Lehouck A, et al. (2010) Vitamin d deficiency is highly prevalent in copd and correlates with variants in the vitamin d-binding gene. Thorax 65: 215-220.

12. Shaheen SO, Jameson KA, Robinson SM, Boucher BJ, Syddall HE, et al. (2011) Relationship of vitamin d status to adult lung function and copd. Thorax 66: 692-628.

13. Berg I, Hanson C, Sayles H, Romberger D, Nelson A, et al. (2013) Vitamin D, vitamin $\mathrm{D}$ binding protein, lung function and structure in copd. Respir Med 107 1578-1588.

14. Hansen JG, Gao W, Dupuis J, O'Connor GT, Tang W, et al. (2015) Association of 25-hydroxyvitamin d status and genetic variation in the vitamin d metabolic pathway with fev1 in the framingham heart study. Respir Res 16: 81.

15. Miller MR, Hankinson J, Brusasco V, Burgos F, Casaburi R, et al. (2005) Standardisation of spirometry. Eur Respir J 26: 319-338.

16. Koyama H, Nishimura K, Ikeda A, Tsukino M, Izumi T (1998) A comparison of different methods of spirometric measurement selection. Respir Med 92: 498504.

17. Japan Society of Chest Diseases (2001) The predicted values of pulmonary function testing and artrial blood gas in japanese [in japanese]. Jpn J Thorac Dis 39: appendix.

18. Osaka D, Shibata Y, Abe S, Inoue S, Tokairin Y, et al. (2010) Relationship between habit of cigarette smoking and airflow limitation in healthy japanese individuals: The takahata study. Intern Med 49: 1489-1499.

19. Holick MF, Binkley NC, Bischoff-Ferrari HA, Gordon CM, Hanley DA, et al. (2011) Evaluation, treatment, and prevention of vitamin d deficiency: An endocrine society clinical practice guideline. J Clin Endocrinol Metab 96: 19111930.

20. Fukuchi Y, Nishimura M, Ichinose M, Adachi M, Nagai A, et al. (2004) Copd in japan: The nippon copd epidemiology study. Respirology 9: 458-465. 